\title{
Circulating cytokine levels in patients with rheumatoid arthritis: results of a double blind trial with sulphasalazine
}

\author{
V A Danis, Gradislava M Franic, Deborah A Rathjen, R M Laurent, P M Brooks
}

\begin{abstract}
Interleukin 1 (IL-1), IL-6, and tumour necrosis factor (TNF) $\alpha$ are pleiotropic cytokines produced predominantly by macrophages which have been implicated in the pathogenesis of rheumatoid arthritis (RA). Sulphasalazine has been shown to have disease modifying properties and to inhibit the production of cytokines in vitro. To evaluate the effect of sulphasalazine on cytokine production in vivo, serum cytokine levels were measured in a group of patients with RA entered into a randomised controlled trial. Serum levels of IL-1 $\alpha, I L-1 \beta, I L-6$, and TNF $\alpha$ were measured at baseline and at two monthly intervals for six months in 17 patients receiving sulphasalazine and in 22 patients treated with placebo. The two groups of patients had a similar age and sex distribution, had had RA for less than a year, had no joint erosions, and had not been treated previously with any other disease modifying drugs.
\end{abstract}

In the 39 patients studied IL-1 $\alpha$ was detected $(>0.1 \mathrm{ng} / \mathrm{ml})$ at baseline in 14 patients (median $0.24 \mathrm{ng} / \mathrm{ml}$ ), IL-1 $\beta$ in 25 patients (median $1.0 \mathrm{ng} / \mathrm{ml}$ ), TNF $\alpha$ in 27 patients (median $1.2 \mathrm{ng} / \mathrm{ml}$ ), and IL-6 in 33 patients (median $0.44 \mathrm{ng} / \mathrm{ml}$ ). In the group treated with sulphasalazine there was a progressive and significant decline in serum IL-1 $\alpha, I L-1 \beta$, and TNF $\alpha$ levels over the six month period (median levels at six months were $<0.1,0.12$, and $0.44 \mathrm{ng} / \mathrm{ml}$ respectively). Interleukin 6 levels were significantly reduced only at the four month time point (median level of $\mathbf{0 . 2 3}$ $\mathrm{ng} / \mathrm{ml}$ ). These reductions were associated with improvements in clinical and laboratory measures of disease activity. In contrast patients receiving the placebo showed no changes in serum cytokine levels and no improvement in clinical and laboratory indices of disease activity. These results suggest that sulphasalazine may exert its disease modifying effect partly by suppressing cytokine production in vivo.

(Ann Rheum Dis 1992; 51: 946-950)

Cytokines have been implicated as important mediators of inflammation and joint destruction in rheumatoid arthritis (RA). ${ }^{1}$ The development of sensitive immunoassays for cytokines has made it possible to show increased levels of some cytokines in the blood of patients with RA. More importantly increased levels of interleukin $1 \beta(\text { IL-1 } \beta)^{2-4}$ and tumour necrosis factor $\alpha$ (TNF $\alpha)^{5}{ }^{6}$ have been associated with disease severity in patients with RA. Although circu- lating IL- 6 has been detected in many patients with arthritis ${ }^{8}$ the levels in patients with RA and patients with other inflammatory arthritides were not significantly higher than in patients with non-inflammatory arthritis. ${ }^{9}{ }^{10}$ Circulating levels of IL- $\alpha$ in patients with RA were found to be low and not significantly different from normal control subjects. ${ }^{4}{ }^{11}$

The determination of circulating cytokines may prove to have prognostic value particularly IL-1 $\beta$ and TNF $\alpha$. There have been several anecdotal reports that the blood levels of certain cytokines (IL-l $\alpha$ and TNF $\alpha$ ) can be decreased during successful treatment with disease modifying drugs. ${ }^{11}{ }^{12}$ Sulphasalazine is a drug that has been found to possess disease modifying properties. ${ }^{13}$ It has also been shown ${ }^{14}$ to inhibit cytokine production in vitro (Danis V A et al, unpublished results). We performed a multicentre randomised controlled trial of sulphasalazine (as Salazopyrine-En tabs, KabiPharmacia) in the treatment of RA in which we showed a significant effect of sulphasalazine over placebo (Australian Multicentre Trial Group, unpublished results). We now report that patients receiving the active drug also had progressive and significant reductions in circulating cytokine levels associated with improvements in clinical and laboratory measures of disease activity.

\section{Patients and methods}

PATIENTS

Patients with classical or definite RA of less than 12 months' duration and with no evidence of joint erosions were entered into a randomised controlled trial of Salazopyrine-En tabs. Patients were clinically reviewed at monthly intervals and blood was collected on each occasion. The study was approved by the institutional ethics committee. Serum samples were collected every two months for six months, aliquoted, and stored at $-20^{\circ} \mathrm{C}$ until assayed for cytokines. Thirty nine patients with sequential serum samples (baseline, two, four, and six months) were selected for study. Seventeen of these patients were receiving sulphasalazine $(2 \mathrm{~g}$ daily). The mean (SD) age was 51 (11), the female to male ratio was $14: 3$, and 12 of the 17 patients were rheumatoid factor positive. The remaining 22 patients who were receiving placebo had a mean (SD) age of 55 (12) years, a female to male ratio of $16: 6$, and 11 of the 22 patients were rheumatoid factor positive. Standard clinical and biochemical measures of disease activity were used including the daily living score which was based on the health assessment questionnaire of Fries et al. ${ }^{15}$ 
CYTOKINE MEASUREMENT AND TESTS FOR SPECIFICITY

Sandwich enzyme linked immunosorbent assays (ELISAs) specific for IL-1 $\alpha$, IL-1 $\beta$, IL-6, and TNF $\alpha$ were developed and used as described previously (Danis V A et al, unpublished results; Danis et $a{ }^{16}$ ). Serum samples were assayed undiluted and without extraction. Recovery of cytokine immunoreactivity of spiked serum samples was $88,84,81$, and $68 \%$ for recombinant IL-1 $\alpha$, IL-1 $\beta$, IL- 6 , and TNF $\alpha$ respectively. Potential false positives in the ELISAs may be produced by human antibodies directed against murine, goat, or sheep IgG as was found by Helle et al. ${ }^{8}$ Unlike the latter study, however, we did not find any decrease in IL-1 $\alpha$ or IL-1 $\beta$ levels when assayed in the presence of normal sheep IgG. Furthermore when the IL-1 $\alpha$ ELISA was modified so that the capture antibody was a murine monoclonal IgG and the labelled antibody was sheep IgG, there was also no difference in the determination of IL-1 $\alpha$ in serum samples. Finally the same sample of serum was sequentially placed on ELISA plates beginning with IL-1 $\alpha$, then IL$1 \beta$, and finally TNF $\alpha$. There was no cross reactivity between these assays. Interleukin 6 determinations were performed separately at a later stage. Consequently any reactivity in human serum samples to sheep IgG or to cross reactive epitopes on murine or goat IgG would be absorbed out in the first reaction (affecting only the IL-1 $\alpha$ determinations). In fact most samples had low immunoreactivity in the IL-1 $\alpha$ ELISA. Samples from individual patients were measured on the same plate and intra-assay variation was estimated at $7 \%$ for IL-6, $12 \%$ for IL- $1 \alpha$ and TNF $\alpha$, and $20 \%$ for IL- $1 \beta$.

The assays were apparently unaffected by the presence of rheumatoid factors in the serum samples as there was no relation between rheumatoid factor titre and cytokine levels. The dilution of known amounts of cytokines in serum samples containing high titres of rheumatoid factor did not affect the determination of IL- $1 \alpha$, IL-1 $\beta$ or IL-6, although the measure of TNF $\alpha$ was reduced by up to $50 \%$, indicating some non-specific interference by rheumatoid factor in the TNF $\alpha$ assay.

Samples of serum with high levels of IL-l $\alpha$, IL-1 $\beta$, or TNF $\alpha$ and a sample of synovial fluid containing a high level of IL-6 were chromatographed on Sephadex G75 and G200 columns (Pharmacia, $30 \times 1 \mathrm{~cm}$ column, $0.5 \mathrm{ml}$ sample volume). Serum cytokines invariably eluted at the void volume (>150 kilodaltons) though recombinant cytokines spiked into normal serum also eluted at the void volume. This suggests that cytokines in serum are rapidly bound to a large molecular weight carrier protein. Possible candidates include $\alpha_{2}$ macroglobulin ${ }^{17}{ }^{18}$ and C3. ${ }^{19}$ Interleukin 6 in synovial fluid eluted at the appropriate volume (22-26 kilodaltons by molecular weight markers) though IL-1 $\beta$ spiked into synovial fluid still eluted at the void volume (data not shown).

\section{STATISTICAL ANALYYSIS}

The Wilcoxon signed rank test was used. Data in the figures are medians (interquartile range) and data in the tables are mean (SD) values.

\section{Results}

Figures $1-4$ summarise the changes in serum cytokine levels in patients receiving sulphasalazine or placebo. The data include only those subjects who were positive for the cytokine tested at any time over the six month period of study. Of the 39 patients 33 were positive for IL-6 (18 in the placebo and 15 in the sulphasalazine group), 27 were positive for TNF $\alpha$ (14 in the placebo and 13 in the sulphasalazine group), 25 were positive for IL-1 $\beta$ (14 in the placebo and 11 in the sulphasalazine group), and 14 were positive for IL-1 $\alpha$ (eight in the placebo and six in the sulphasalazine group). All four cytokines were detected in 7/39 patients, three of the four cytokines in 16/39 patients, two of the four cytokines in 9/39 patients, and only one of the four cytokines in $7 / 39$ patients. There was no obvious pattern of clustering of cytokines in any of these subgroups. The data represented in figs $1-4$ clearly show that serum cytokine levels were consistently reduced over time in the treatment group but that there are no changes in the placebo group over the six month period. The only exception is serum IL-6 levels which do not change much even in the treatment group. Although there was a slight decrease in serum IL-6 levels at four months in the treatment group, it was not sustained at six months.

The table summarises the clinical and laboratory measures of disease activity for the two groups over the trial period. Mann-Whitney tests verified that there were no significant differences in any of these variables at baseline in the two groups of patients. Although patients receiving the placebo achieved improvements in some clinical parameters such as the Ritchie

Clinical and laboratory measures of disease activity in the patients with rheumatoid arthritis at baseline and after six months

\begin{tabular}{|c|c|c|c|c|}
\hline \multirow[t]{2}{*}{ Parameter* } & \multicolumn{2}{|c|}{ Placebo group } & \multicolumn{2}{|c|}{ Group treated with sulphasalazine } \\
\hline & Baseline & Six months & Baseline & Six months \\
\hline $\begin{array}{l}\text { Ritchie joint score } \\
\text { Pain score } \\
\text { EMS (hours) } \\
\text { Activities of daily living score } \\
\text { ESR (mm/hour) } \\
\text { CRP (mg/l) } \\
\text { Hyaluronic acid ( } \mu \mathrm{g} / \mathrm{l}) \\
\text { IgM RF (IU/ml) } \\
\text { IgA RF (IU/ml) }\end{array}$ & $\begin{array}{l}13 \cdot 5(10 \cdot 6) \\
36 \cdot 0(19 \cdot 7) \\
2 \cdot 7(1 \cdot 1) \\
1 \cdot 7(0 \cdot 9) \\
24 \cdot 9(20 \cdot 9) \\
13 \cdot 6(16 \cdot 8) \\
54 \cdot 9(36 \cdot 3) \\
282(485) \\
6.7(9 \cdot 8)\end{array}$ & $\begin{aligned} 9 \cdot 2(7.8)(p=0.04) \dagger \\
34 \cdot 1(24 \cdot 1)(p=0.59) \\
2.6(1.2)(p=0.66) \\
1.2(0.4)(p=0.01) \dagger \\
35 \cdot 2(30.5)(p=0.04) \dagger \\
13.3(15.6)(p=0.69) \\
111(110)(p=0.007) \dagger \\
236(559)(p=0.93) \\
7.5(10.9)(p=0.24)\end{aligned}$ & $\begin{array}{l}13 \cdot 3(10 \cdot 6) \\
31 \cdot 1(17 \cdot 5) \\
3 \cdot 1(1 \cdot 3) \\
1 \cdot 6(0 \cdot 5) \\
25 \cdot 2(19 \cdot 6) \\
18 \cdot 7(18 \cdot 6) \\
61 \cdot 6(34 \cdot 6) \\
521(1001) \\
33.6(62 \cdot 1)\end{array}$ & 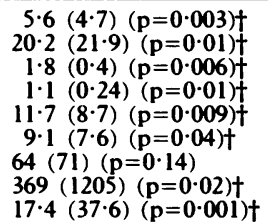 \\
\hline
\end{tabular}

${ }^{\prime} \mathrm{EMS}=$ duration of early morning stiffness; $\mathbf{E S R}=$ erythrocyte sedimentation rate; $C \mathrm{CRP}=\mathrm{C}$, reactive protein; $\mathrm{RF}=$ rheumatoid factor. tStatistically significant compared with baseline. 
Figure 1 Effect of sulphasalazine treatment on serum tumour necrosis factor $\alpha(T N F \alpha)$ concentrations in patients with rheumatoid arthritis. ${ }^{*} p<0.01$ compared with baseline.
Figure 2 Effect of sulphasalazine treatment on serum interleukin $1 \beta$ (IL-1B) concentrations in patients with rheumatoid arthritis. ${ }^{*} p<0.01$, $\# p<0.05$ compared with baseline.
Figure 3 Effect of sulphasalazine treatment on serum interleukin $I \alpha$ $(I L-I \alpha)$ concentrations in patients with rheumatoid arthritis. ${ }^{*} p<0.05$ compared with baseline.
Figure 4 Effect of sulphasalazine treatment on serum interleukin $6(I L-6)$ concentrations in patients with rheumatoid arthritis. ${ }^{*} p<0.05$ compared with baseline.
Placebo treatment
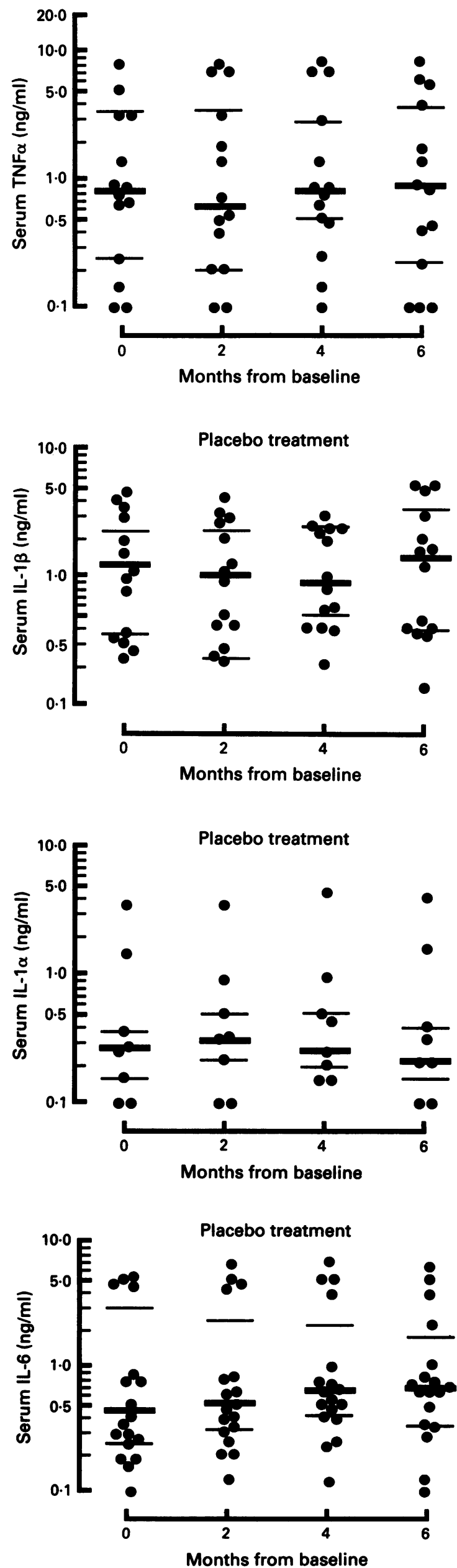

Sulphasalazine treatment

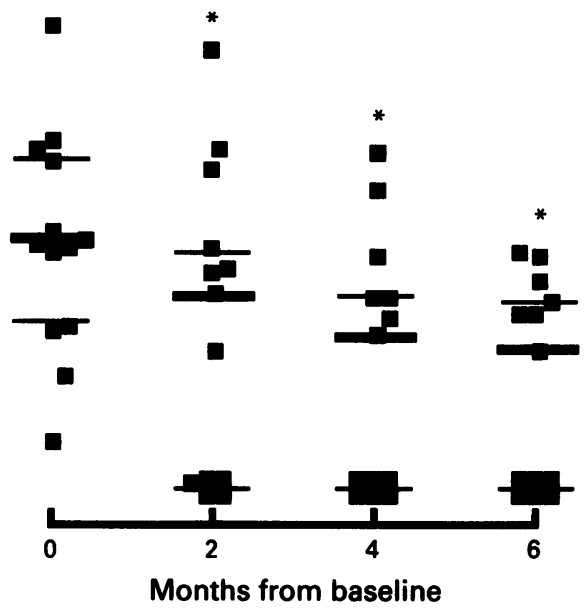

Sulphasalazine treatment

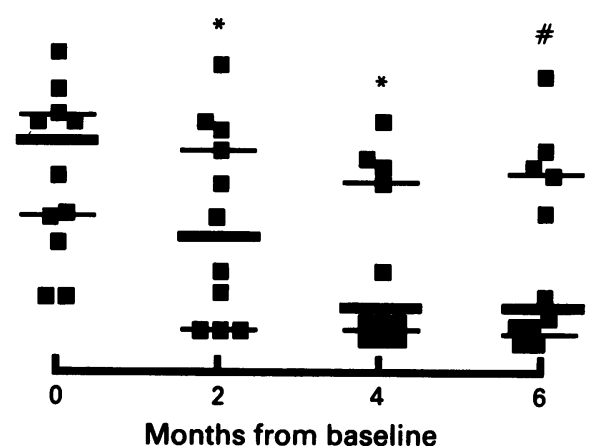

Sulphasalazine treatment

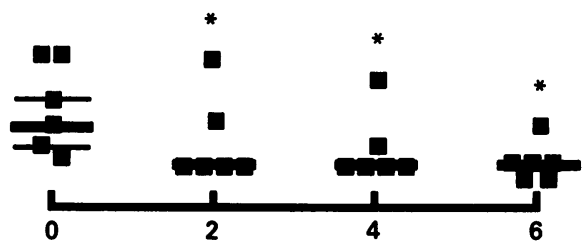

Months from baseline

Sulphasalazine treatment

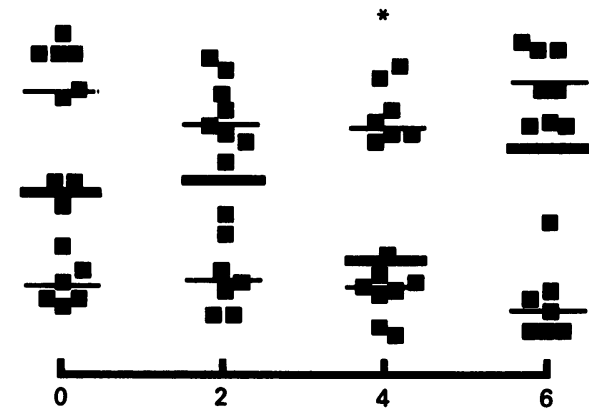

Months from baseline 
index and the activities of daily living score there were no improvements in any of the laboratory parameters. In fact changes in the erythrocyte sedimentation rate and serum hyaluronic acid levels indicate the continuing progression of disease. ${ }^{20}$ In contrast patients receiving sulphasalazine showed improvements in all clinical and laboratory parameters. Stable levels of serum hyaluronic acid indicate control of disease progression. Therefore changes in serum cytokine levels in patients receiving sulphasalazine are clearly associated with clinical improvement.

\section{Discussion}

We have shown that successful treatment with the disease modifying drug sulphasalazine is associated with reductions in serum levels of IL-1 $\alpha$, IL-1 $\beta$, and TNF $\alpha$ if these cytokines are present in detectable amounts before treatment. At least one of these three cytokines was detected in most patients (36/39). Although IL-6 was detected in the serum of most patients with RA (33/39), it was unaffected by treatment with sulphasalazine. This is consistent with our observations on the effects of sulphasalazine on cytokine production in vitro where we found that much higher concentrations of sulphasalazine $(50 \mu \mathrm{g} / \mathrm{ml})$ were required to inhibit IL-6 production compared with IL-1 or TNF $\alpha$ production (12-25 $\mu \mathrm{g} / \mathrm{ml}$ ) (Danis V A et al, unpublished results). The upper range of serum concentrations of sulphasalazine in patients is $12-25 \mu \mathrm{g} / \mathrm{ml} .^{21}$ The source of the cytokines in serum is not known but activated macrophages may be the main cellular source. Endothelial cells stimulated by cytokines produce significant amounts of IL- $6^{22}$ but only small amounts of IL-1 and TNF $\alpha .{ }^{23} 24$

In this study there was a significant decrease in the standard clinical and laboratory parameters of disease activity in those patients receiving Sap-en tabs whereas those patients receiving placebo showed no such reduction. Sulphasalazine has been shown to be beneficial in the treatment of $\mathbf{R A}^{25-27}$ (Australian Multicentre Trial Group, unpublished results) and of ankylosing spondylitis. 28 In a comparative study sulphasalazine significantly slowed the rate of bone erosion in patients with $\mathrm{RA}$ compared with hydroxychloroquine. ${ }^{30}$ Like all disease modifying drugs, sulphasalazine has a spectrum of adverse reactions including rashes and gastrointestinal events. It is, however, well tolerated by patients compared with similar drugs. ${ }^{31} 32$

This study shows that sulphasalazine may inhibit cytokine production in vivo, though we do not know if this is a primary effect of the drug in vivo or a change secondary to the suppresion of inflammation. Cytokine levels were significantly reduced after two to four months of treatment with sulphasalazine. Disease activity, however, was not assessed until after four and six months when there were significant improvements in the clinical and laboratory measures (data presented only for six months). Therefore it was not possible to determine whether the changes in serum cyto- kine levels preceded clinical improvement. Our in vitro studies suggest that sulphasalazine may inhibit cytokine production as a primary mode of action of the drug (Danis V A et al, unpublished results). Moreover the minimal effect of sulphasalazine treatment on circulating IL-6 levels is also consistent with the in vitro data (Danis V A et al, unpublished data). There is preliminary evidence to suggest that IL-6 may have a protective and anabolic role in connective tissues-for example, by stimulating chondrocyte growth, the production of transforming growth factor $\beta$, and the tissue inhibitor of metalloproteinases by chondrocytes (P-A Guerne et al, unpublished results). Interleukin 6 may have a protective role in arthritis and it may not be desirable to suppress its production with disease modifying drugs. Suppression of the production of potentially pathogenetic cytokines (IL-1 and TNF $\alpha$ ) may be one mechanism of the disease modifying action of sulphasalazine in patients with RA.

This work has been supported by grants from the National Health and Medical Research Council, The Arthritis Foundation of Australia, The Medical Foundation (The University of Sydney), the Allan Stephens Trust (North Sydney Rotary), the AMP Society and Trust Funds of the Royal North - Shore Hospital. We are grateful to Dr S Poole and the National Institute for Biological Standards and Control, United Kingdom, for the supply of antisera to IL-1 $\alpha$, IL-1 $\beta$, and IL- 6 used in the ELISAs and WHO international cytokine standards.

1 Arend W P, Dayer J-M. Cytokines and cytokine inhibitors or antagonists in rheumatoid arthritis. Arthritis Rheum 1990; 33: 305-15.

2 Eastgate J A, Symons J A, Wood N C, Grinlinton F M, Di Giovine F S, Duff G W. Correlation of plasma interleukin 1 levels with disease activity in rheumatoid arthritis. Lancet 1988; ii: 706-9.

3 Maury C P, Andersson L C, Teppo A M, Partanen S, Juvonen E. Mechanism of anaemia in rheumatoid arthritis: demonstration of raised interleukin 1 beta concentrations in anaemic patients and of interleukin 1 mediated suppression of normal erythropoiesis and proliferation of human of normal erythropoiesis and proliferation of human 1988; 47: 972-8.

4 Symons J A, McDowell T L M, Di Giovine F S, Wood N C Capper $S \mathrm{~J}$, Duff $\mathrm{G}$ W. Interleukin 1 in rheumatoid arthritis: potentiation of immune responses within the joint. Lymphokine Res 1989; 8: 365-72.

5 Saxone T, Palladino M A Jr, Heineg D, Talal N, Wollheim F A. Detection of tumor necrosis factor alpha but not tumor necrosis factor beta in rheumatoid arthritis synovial fluid and serum. Arthritis Rheum 1988; 31: 1041-5.

6 Tetta C, Camussi G, Modena V, Di Vittorio C, Baglioni C. Tumour necrosis factor in serum and synovial fluid of patients with active and severe arthritis. Ann Rheum Dis 1990; 49: 665-7.

7 Hovdenes J, Kvien T K, Hovdenes A B. IL-6 in synovial fluids, plasma and supernatants from cultured cells of patients with rheumatoid arthritis and other inflammatory arthritides. Scand $\mathcal{F}$ Rheumatol 1990; 19: 177-82.

8 Helle M, Boeije L, de Groot E, de Vos A, Aarden L. Sensitive ELISA for interleukin-6. Detection of IL-6 in biological fluids: synovial fluids and sera. 7 Immunol Methods 1991; 138: 47-56.

9 Waage A, Kaufmann C, Espevik T, Husby G. Interleukin-6 in synovial fluid from patients with arthritis. Clin Immuno Immunopathol 1989; 50: 394-8.

10 Jensen $H$ S, Tvede N, Diamant $M$, et al. Elastolytic activity of human monocytes from synovial fluid and blood of patients with arthritis. Relations to levels of interleukin 6 patients with arthritis. Relations to levels of interieukin and soluble inter
1991; 20: 83-90.

11 Eastgate J A, Symons J A, Wood N C, Capper S J, Duff G W Plasma levels of interleukin 1 alpha in rheumatoid arthritis. Br F Rheumatol 1991; 30: 295-7.

12 Roubenoff R, Holland S M, Stevens M B. Elevated serum tumor necrosis factor in rheumatoid arthritis [abstract]. Arthritis Rheum 1989; 32 (suppl): Dl63.

13 Porter D R, Capell H A. The use of sulphasalazine as a disease modifying antirheumatic drug. Baillieres Clin Rheumatol 1990; 4: 535-51.

14 Remvig L, Andersen B. Salicyloazosulfapyridine (salazopyrin) effect on endotoxin-induced production of interleukin-1like factor from human monocytes in vitro. Scand $f$ Rheumatol 1990; 19: 11-6.

15 Fries J F, Spity P W, Young D Y. The dimensions of health outcomes: the Health Assessment Questionnaire, disability and pain scales. I Rheumatol 1982; 9: 789-93.

16 Danis V A, Franic G M, Rathien D A, Brooks P M. The 
effects of granulocyte-macrophage colony stimulating factor (GM-CSF), interleukin 2 (IL-2), interferon (IFN)gamma, tumour necrosis factor (TNF)- $(\ell$ and IL-6 on the production of immunoreactive IL- 1 and TNF- $t \ell$ by human monocytes. Clin Exp Immunol 1991; 85: 143-50.

17 Borth W, Luger T A. Identification of 12 -macroglobulin as a cytokine binding plasma protein: binding of interleukin if to "F" (22-macroglobulin. I Biol Chem 1989; 264 5818-25.

18 Matsuda T, Hirano T, Nagasawa S, Kishimoto T. Identification of (12-macroglobulin as a carrier protein for IL-6. fication of (2-macroglobulin as a

19 Borth W, Urbanski A, Prohaska R, Susani M, Luger T A Binding of recombinant interleukin $I f$ to the third component of complement and 12 -macroglobulin after activation of serum by immune complexes. Blood 1990; 75: 2388-95.

20 Fries I F, Spitz P, Kraines R G, Holman H R. Measurement of patient outcome of arthritis. Arthritis Rhewm 1980; 23: of patient

21 Pullar T, Hunter J A, Capell H A. Sulphasalazine in the treatment of rheumatoid arthritis: relationship of dose and serum levels to efficacy. Br $\mathcal{Y}$ Rheumatol $1985 ; 24: 269-76$.

22 Podor T J, Jirik F R, Loskutoff D J, Carson D A, Lotz M. Human endothelial cells produce IL-6. Lack of responses to exogenous IL-6. Ann N Y Acad Sci 1989; 557: 374-85.

23 Shanahan W R Jr, Hancock W W, Korn J H. Expression of IL-1 and tumor necrosis factor by endothelial cells: role in stimulating fibroblast $\mathrm{PGE}_{2}$ synthesis. $\mathcal{F}$ Exp Pathol 1989; 4: 17-27.

24 Poubelle P E, Grassi J, Pradelles P, Marceau F. Pharmacological modulation of interleukin 1 production by cultured endothelial cells from human umbilical veins. Immunopharmacology 1990; 19: 121-30.

25 McConkey B, Amos R S, Durham S, Forster P J G, Hubball $S, W a l s h ~ L$. Sulphasalazine in rheumatoid arthritis. $B M Y$ 1980; 280: 442-4.

26 Pullar T, Hunter J A, Capell H A. Sulphasalazine in rheumatoid arthritis: a possible blind comparison of sulphasalazine with placebo and sodium aurothiomalate. $B M \mathcal{Y}$ 1983; 287: 1102-4.

27 Farr M, Tunn E, Crockson A P, Bacon P A. The long term effects of sulphasalazine in the treatment of rheumatoid arthritis and a comparative study with penicillamine. Clin Rheumatol 1984; 3: 473-82.

28 Dougados M, Bouvier P, Amor B. Sulphasalazine in ankylosing spondylitis: a double blind controlled study in 60 patients. BMF 1986; 293: 911-4.

29 Nissila M, Lehtinen K, Leirisalo-Repo M, Luukkainen $R$, Mutru O, Yli-Kerttula U. Sulphasalazine in the treatment of ankylosing spondylitis. Arthritis Rheum 1988; 31: of ankylo

30 Van der Heijde D M, van Riel P L, Nuver-Zwart I H Gribnau F W, van de Putte L B. Effects of hydroxychloroquine and sulphasalazine on progression of joint damage in rheumatoid arthritis. Lancet 1989; i: 1036-8.

31 Donovan S, Hawley S, MacCarthy J, Scott D L. Tolerability of enteric coated sulphasalazine in rheumatoid arthritis: results of a cooperating clinics study. Br $\mathcal{F}$ Rheumatol 1990 ; 29: $201-4$.

32 Bax D, Amos R. Sulphasalazine: a safe effective agent for prolonged control of rheumatoid arthritis. A comparison with sodium aurothiomalate. Ann Rheum Dis 1988; 44: 194-8. 